\title{
How long is the SLAC Gallery?
}

\author{
Hans Imfeld \\ SLAC, Stanford University, CA 94025
}

The SLAC Communications Department contacted Metrology to inquire about the length of SLAC’s Gallery, building 002.

Initially, Metrology’s Alignment Engineering Group (AEG) proposed to import SLAC’s orthophotos into a CAD platform (Microstation). A draftsman could then graphically pick two points at the Gallery's extreme and measure the distance between them (3074.8m). This would be a fast method of producing the length of the gallery, but could be in error by several meters due to photo rectification. The Communications Department required a more accurate measurement.

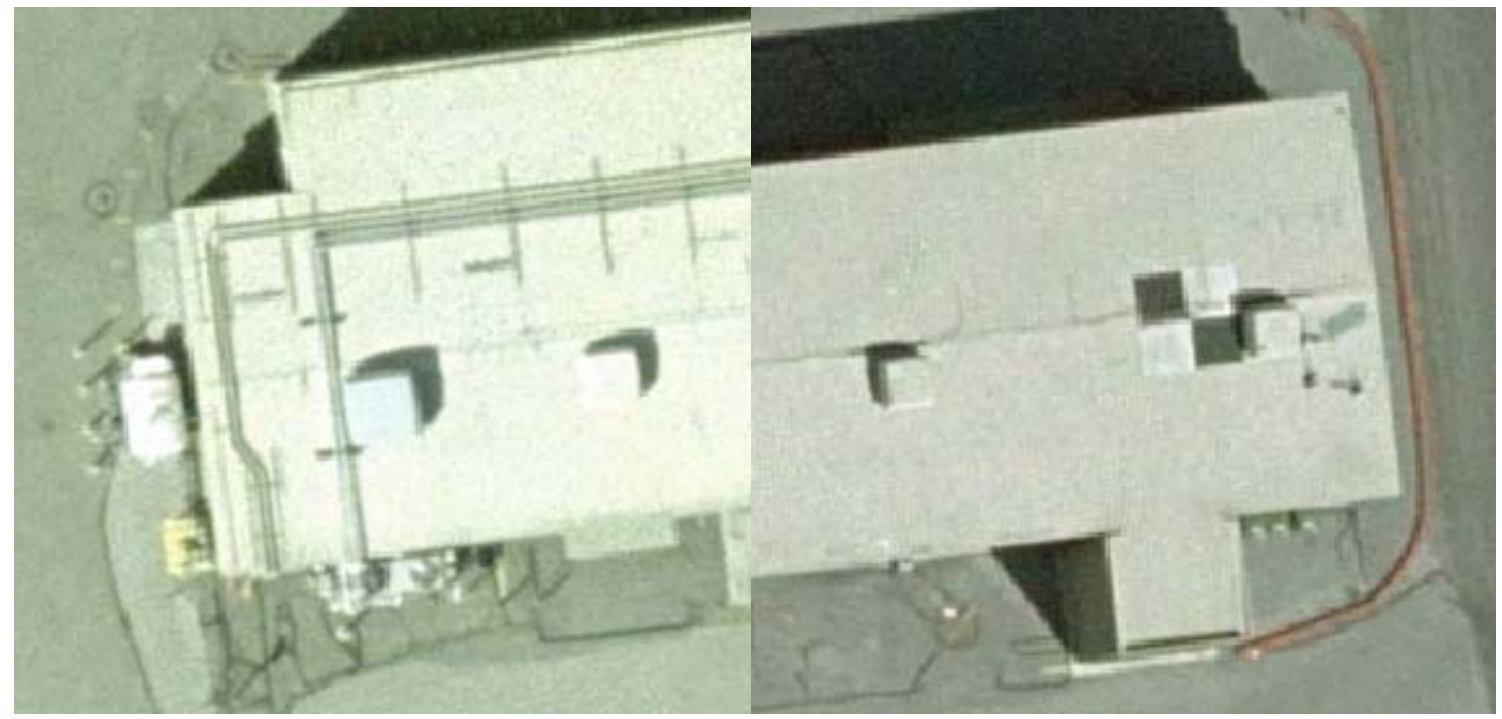

Figure 1: SLAC orthophotos of Gallery ends (west/east)

Survey crews of AEG measured the length of the gallery using two methods: an RTK GPS survey and a traditional traverse using a total station.

\section{GPS (Leica System 500)}

A GPS antenna was positioned approximately $15 \mathrm{~cm}$ above the gallery roof near the four exterior corners of the gallery. A global position was measured at each corner and recorded. The length of the gallery was then computed by calculating the 3D distance between the two southerly points and between the two northerly points. The two distances agreed to within $4 \mathrm{~cm}$. 


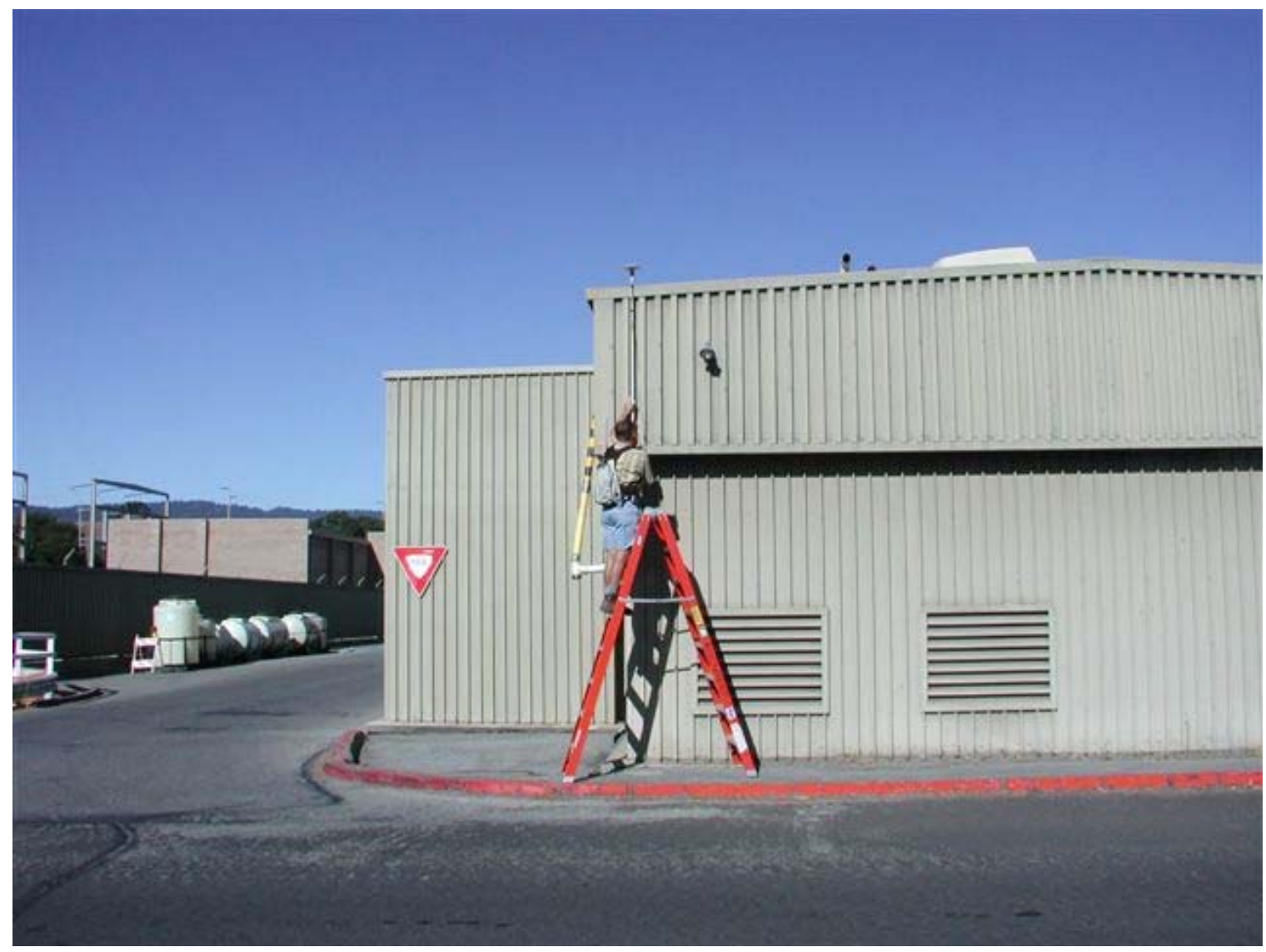

Figure 2: GPS measurement of Gallery east, photo courtesy of Michael Perry 


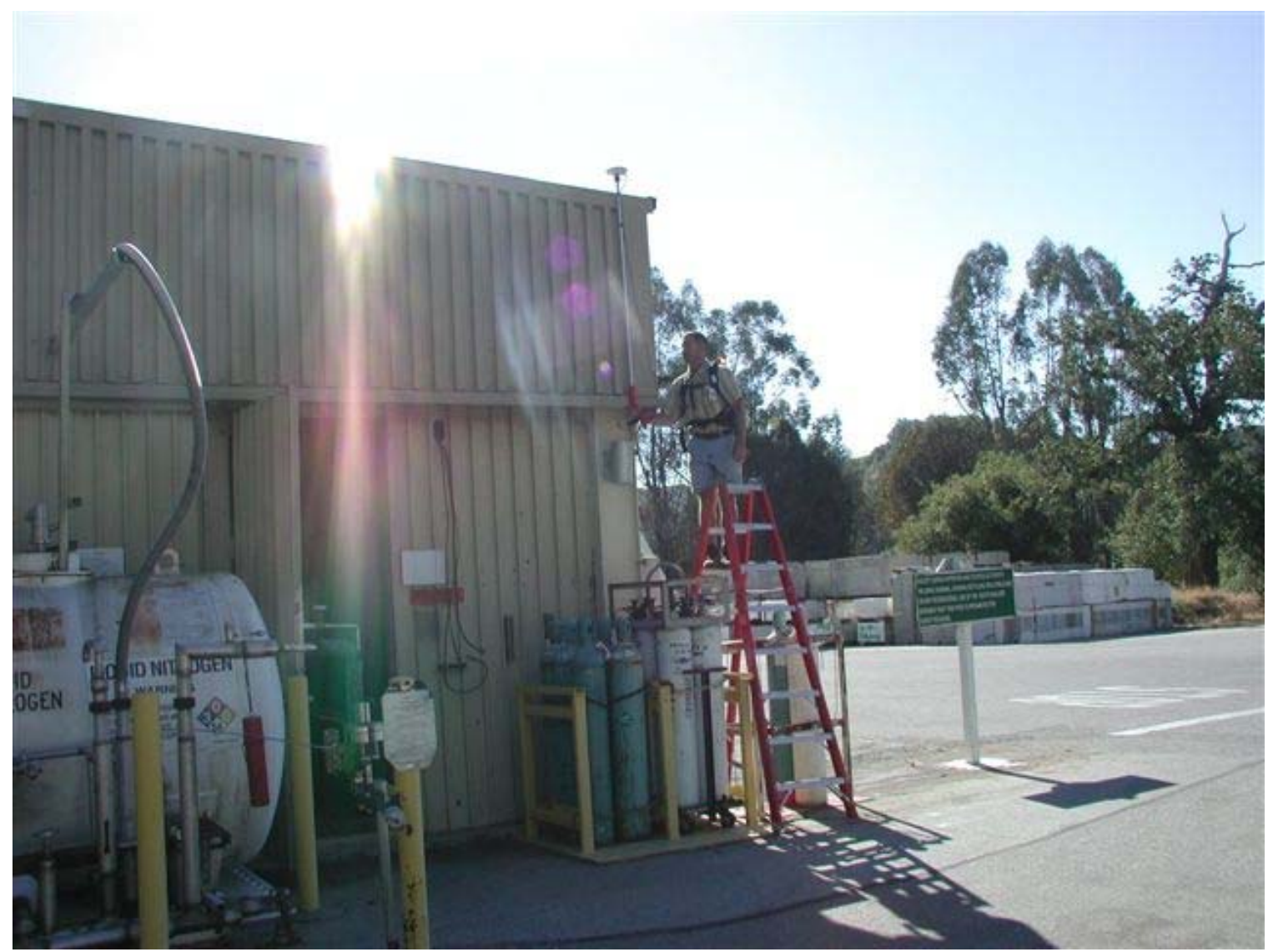

Figure 3: GPS measurement of Gallery west, photo courtesy of Michael Perry

\begin{tabular}{|c|c|c|c|c|}
\hline ID & $\mathbf{X}$ & $\mathbf{Y}$ & $\overline{\mathbf{Z}}$ & 3D Distance \\
\hline EAST_S & -2703162.507 & -4291739.382 & 3854234.621 & 3073.773 \\
\hline WEST_S & -2705888.547 & -4290363.988 & 3853880.955 & \\
\hline EAST_N & -2703160.725 & -4291733.914 & 3854241.978 & 3073.734 \\
\hline WEST_N & -2705886.789 & -4290358.692 & 3853888.169 & \\
\hline
\end{tabular}

The GPS length of the Gallery is the average length of the observations minus the antenna pole diameter (1 inch): 3073.73m.

\section{Traditional Traverse (Leica 1105)}

A survey crew set 5 temporary points along the south gallery road. A traverse was run through these points. At both ends, a reflectorless observation was made to the southerly roof corners of the gallery structure. The measurements were run twice. A coordinate of $(0,0,100)$ was assigned to the first point and onboard software computed the summation of each subsequent observation's coordinate. Prism offsets and atmospheric conditions were corrected by the onboard software. 


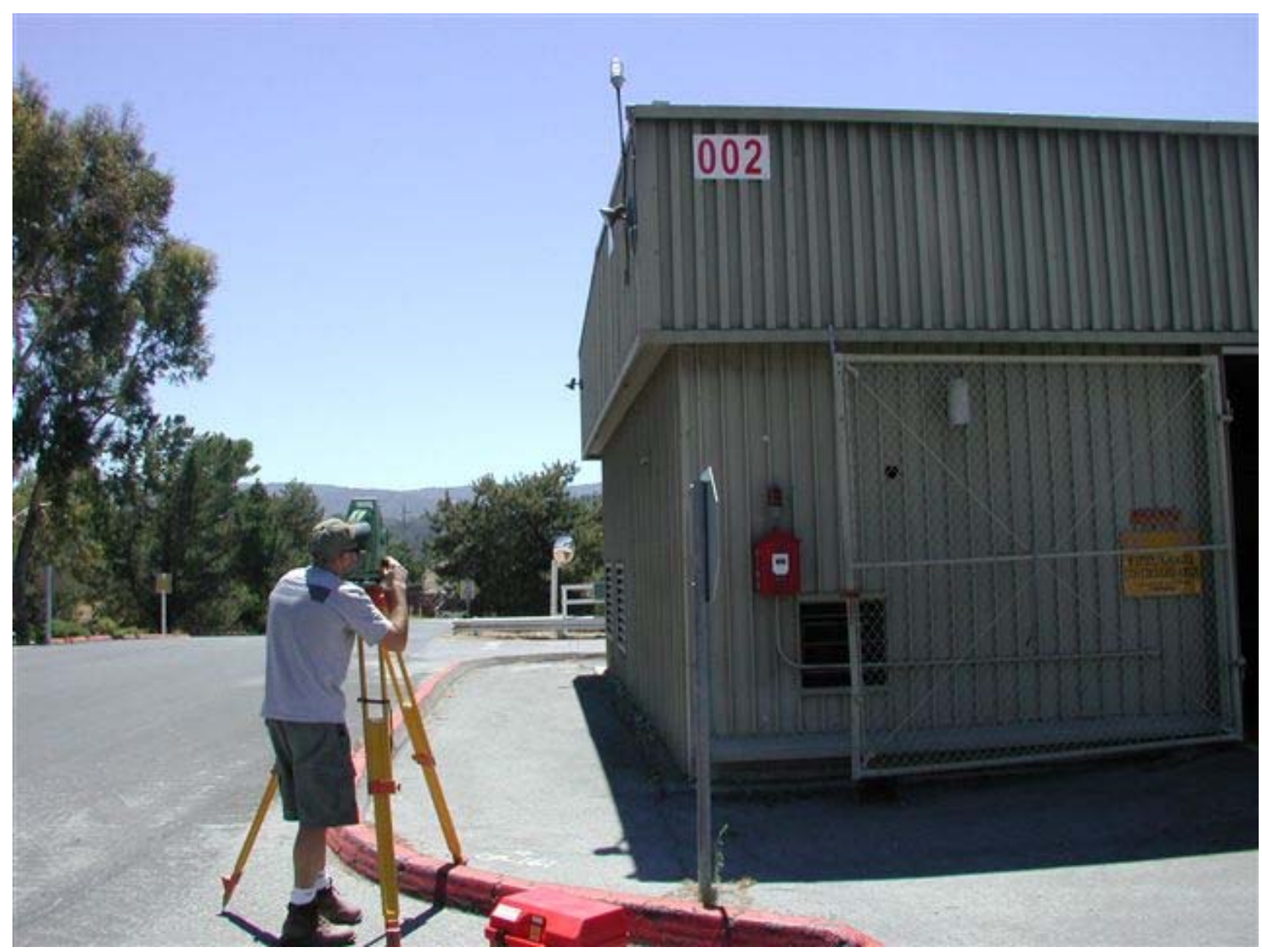

Figure 4: Total station measurement of Gallery east, photo courtesy of Hans Imfeld

\begin{tabular}{|lllll|}
\hline \multicolumn{4}{|c|}{ Table 2: } & Traversed building corner coordinates (local coordinate, meters) \\
\hline ID & Easting & Northing & Elevation & 3D Distance \\
WEST & -7.375 & 15.387 & $\mathbf{1 0 4 . 5 2 9}$ & 3073.719 \\
EAST & -1.377 & 3089.062 & $\mathbf{8 9 . 2 6 2}$ & \\
WS & -7.339 & 15.392 & $\mathbf{1 0 4 . 5 7 1}$ & 3073.687 \\
ES & -1.349 & 3089.035 & $\mathbf{8 9 . 1 8 6}$ & \\
\hline
\end{tabular}

The traversed average length of the Gallery is: $3073.70 \mathrm{~m}$.

How long is the gallery? Since the two methods of observation have similar accuracy and in the interest of keeping it simple, AEG averaged the two methods and determined that the length of the Gallery is $3073.72 \mathrm{~m}$.

\section{Acknowledgements}

The author thanks everyone in the Alignment Engineering Group who helped with the field planning, data collection, data processing, and editing. 